\title{
Whipple Disease
}

National Cancer Institute

\section{Source}

National Cancer Institute. Whipple Disease. NCI Thesaurus. Code C85228.

A systemic infection caused by the Gram-positive bacterium Tropheryma whipplei. It affects the small intestine resulting in malabsorption. Other sites or systems affected by the infection are the joints, central nervous system, and the cardiovascular system. 